\title{
浅谈雨季大树移植技术和提高成活率措施
}

\author{
徐金莲 ${ }^{1}$ 张士卓 $^{2}$
}

1 山东省东营市广饶县乐安公园管理处 2 山东省东营嘉晟建设工程公司

DOI:10.32629/eep.v2i6.315

[摘要] 近几年来, 随着城市建设的不断发展, 城区重点项目建设范围内的大树需要进行保护性迁移。大树移植风险较大, 必须 制定科学合理的施工方案, 安排技术实力较强、经验丰富的的施工单位组织实施。本文根据大树移植的经验, 分析了大树迁移 前的准备工作、迁移技术措施及注意事项,详细阐述了雨季采用方箱移植技术要点、操作步骤等,采取各项切实可行的技术措 施, 以达到提高大树移植成活率的目标。

[关键词] 大树移植; 技术; 成活率

\section{1 大树的基本情况}

1. 1 大树长势情况

该移植树木品种为国槐, 树高约 $10 \mathrm{~m}$, 胸径 $90 \mathrm{~cm}$ (东西 $80 \mathrm{~cm}$ 、南北 $100 \mathrm{~cm})$, 冠幅东西 $7.2 \mathrm{~m}$ 、南北 $6.7 \mathrm{~m}$, 树冠不匀称, 生长势中等偏弱, 树梢已发生干枯, 树干有 $1 / 3$ 已干枯无树皮, 树干中央周围发生空洞。大树细胞再生能力下降, 伤根恢复 慢, 发新根能力弱, 发新根时间较长。

1. 2 迁移季节 (雨季, 7 月 15 号前)

大树迁移可在雨季来临前进行。雨季水分足, 土温适宜, 大气湿度大, 树木蒸腾失水少, 利于发新根和根系生长, 利于 成活。

1. 3 迁移方法为方箱移植

方箱移植土球大, 带须根较多; 方箱固定牢固, 起、运、 种过程中不易散球。

\section{2 大树迁移养护技术措施}

2. 1 大树迁移技术管理措施

2. 1. 1有经验的树木栽培专家进行技术指导, 有操作经 验的人员进行施工养护, 施工人员在施工前进行培训。

2.1.2在较适宜的季节 (雨季) 迁移。

2.1.3迁移方法采用方箱移植。

2. 1. 4挖大穴, 配置适宜的种植土 (改良土壤), 合理修剪, 细致种植, 做到根土密接, 抬高种植。

2.1.5 修剪根系, 切口用刀片修削平滑, 利于生根。

2. 1. 6 种植土用多菌灵消毒, 方形土球周围喷多菌灵消 毒, 预防发生根腐病等。

\section{2 提高成活及复壮技术措施}

2. 2. 1放通气管4根, 提高土壤通气性, 利于生根。

2.2.2 根系喷生根促进剂, 菜乙酸与吲哚丁酸 (1:1) , 200ppm, 促进生根。

2. 2.3 树冠喷抗蒸腾抑制剂, 减少叶片水分。

2.2. 4 树干基部输液, 补充树体水分。

2.2.5 叶面喷肥, 促进生根。

2. 2. 6 种植国槐小苗, 进行桥接, 促进成活生长, 提高今 后生长势。

\section{3 大树迁移方法及操作步骤}

3. 1迁移前的准备工作

3. 1. 1 准备箱板及固定材料, 大树用方箱迁移, 根据现场 及国槐生长状况, 方箱长度 4 米, 宽度 2.5 米, 高度 1 米, 方箱为 梯形, 上下差 $20 \mathrm{~cm}$, 用 $8-10 \mathrm{~cm}$ 厚的板材做方箱, 采购准备固定 材料。

3. 1.2 联系机械, 200 吨、70吨吊车及大拖挂车。

3. 1.3 人员培训, 参加迁移人员, 有大树移植或古树迁移 经验, 迁移前进行技术操作规范、安全等培训。

3.1.4环境清理, 影响大树迁移的周围障碍物及物料进 行清除, 运输道路进行清理或维修。

3. 1.5 树体加固及支持固定, 由于树体有 $1 / 3$ 干枯, 已有 空洞, 迁移前对树体进行加固。在树干 (分支点以下) 上中下 三个部位打三个铁䈨, 然后进行支持固定, 防止开挖后倒伏。

3. 1.6 运输道路整修铺设, 大树运输道路进行整修, 由于 路基不实, 迁移古树前, 进行道路维修, 路基较松的路面铺设 钢板。

3. 1. 7 开挖树穴, 根据大树方形土球大小 (长 4 米, 宽 2.5 米, 高 1 米), 周围大于方形土球 1 米外大开挖树穴 (即树穴规 格 6 米 $\times 4.5$ 米 $\times 1$ 米)。

3. 1. 8准备种植土, 根据大树的特性, 配置种植土。种植 土配比为: 园土: 草炭: 珍珠岩 $2: 1: 1$, 充分混合均匀, 喷酒 多菌灵或掺多菌灵粉剂进行消毒。

3. 1.9 准备通气管, 直径 $10 \mathrm{~cm}$ 的通气管 4 根, 上部 $20 \mathrm{~cm}$ 以 下打孔。

3. 1.10 准备喷雾材料, 架杆、喷雾喷头、喷水管等。

3.1 .11 准备遮荫材料, 钢管数根、 $50 \%$ 或 $70 \%$ 的遮阳网等。

3.1.12准备药剂等, 多菌灵或甲基托布津、菜乙酸和吲 哚丁酸、酒精、抗蒸腾抑制剂、营养液、浇花喷壶、喷雾器、 修枝剪等。

3.2起挖运输大树

3. 2.1 移前修剪, 为了减轻树体重量, 便于吊运种植, 疏 除枯枝、部分过密枝、重叠枝、徒长枝及层间的小枝等, 较 大的大枝回缩部分小枝, 摘除部分树叶。注意控制修剪量。 
3.2.2 树冠喷抗蒸腾抑制剂, 起挖前或起挖后装车前, 树 冠喷一遍抗蒸腾抑制剂, 减少枝叶蒸腾失水。

3. 2. 3 确定方形土球范围, 根据方形土球规格 (长 4 米, 宽 2.5 米), 划出起挖范围。

3. 2. 4 挖掘方形土球, 根据起挖范围, 下挖方形土球, 深 度达 1 米后, 修削四周侧壁, 侧壁要平整光滑。

3.2 .5 上箱板固定, 先上四周箱板, 固定牢固; 然后从两 侧逐渐向内掏底, 上一块底板及相对顶板后固定牢固, 再向 内陶土, 同样方法上第二块底板和顶板, 继续上第三块箱板。 固定牢固。

3.2.6吊装运输, 吊方箱底板两侧, 在底板下方放两根钢 管, 提高承重能力, 树体直立, 慢慢吊移到拖挂车上, 固定牢 固后进行运输。运输过程中速度一定平稳, 较缓慢的安全到 达迁移地点。

\section{3 大树种植}

3. 3. 1 穴低回填土, 种植前, 回填部分土壤, 做成平顶的 长方形土堆, 土堆踩实, 高 $30-40 \mathrm{~cm}$, 控制好种植深度。

3. 3. 2 吊树入穴, 大树缓慢的吊入穴内, 放在长方形土堆 上面, 树干北向朝北, 控制种植深度。大树抬高 $0.5 \mathrm{~m}-1 \mathrm{~m}$ 种植。

3. 3. 3支撑固定, 为防止大树风倒, 大树放好后, 用钢管 进行支撑固定 (三角或四支柱), 树干固定部位放垫物, 以免 损伤树皮。

3. 3. 4 拆卸箱板种植, 先拆卸底板, 底部填土捣实, 四侧 放入通气管 (4根), 回填少量种植土, 踩实, 再拆卸侧板, 四周 根系进行修剪, 用小刀刮平根系切口, 喷生根促进剂 (200ppm 荎乙酸和吲哚丁酸), 然后方形土球周围喷800倍多菌灵随填 种植土随踩实, 深度根茎同种植地面平。

3.3 .5 筑灌水堰, 穴面大小为方形土球外 $20-30 \mathrm{~cm}$, 里面 略高, 外面略低, 穴面外筑高 $20 \mathrm{~cm}$ 左右的灌水堰, 踩实。

3. 3. 6树体输液, 树干下方 $20-30 \mathrm{~cm}$ 高处, 进行输液补充 水分及营养液, 同时输液 2 袋, 并及时进行更换, 连续输液 30 天左右。

3. 3. 7 浇定根水, 种植后及时 (1天内) 浇定根水, 小水漫 灌, 浇透。2-3天后, 在方形土球周围开沟浇生根促进剂, 促进 生根成活。

3. 3.8 树冠复剪, 种植后及时进行复剪。疏除种植前修剪 不理想的枝条、过密枝及迁移过程中损伤枝等。

3. 3. 9 树冠遮阳, 在树体周围 $50 \mathrm{~cm}$ 外架设钢管架杆, 搭设 $50 \%$ 或 $70 \%$ 的遮阳网, 固定牢固。

3. 3. 10 安装喷雾, 树冠安装微喷头喷雾装置。

3. 3. 11 树穴松土, 浇定根水后3-5天, 树穴土壤适宜时进 行穴面松土, 深3-5厘米, 里面浅些、外面适当加深。松土要 细致、全面。

3. 3. 12 种植国槐小苗, 在国槐干基周围种植部分 (3-10 株) 国槐小苗, 成活后 (2019年3月或8月)进行桥接。
3. 4 大树养护管理及复壮

3. 4. 1 干旱性浇水, 干旱季节根据天气、土壤情况及树体 表现及时进行浇水, 一般原则是见干见湿, 防止浇水次数过 多及一次浇水量过大, 影响发新根。

3.4 .2 松土除草, 每次浇水或降大雨后 (雨季除外), 及时 进行树穴松土。

3. 4.3 树冠喷雾, 迁移后, 一般每天喷雾两次, 上午 10 点 左右, 下午 4 点左右。晴天高温或大风天气, 增加喷雾次数。

3. 4. 4 病虫害防治, 迁移后, 设专人定期 (3-5天 1 次) 观察, 发现有病虫害发生, 及时进行防治。为了预防发生病虫害, 每年11月中下旬树体及树穴喷5波美度石硫合剂。

3.4 .5 定期观察, 设专人 (技术人员或专家) 定期 (半月 1 次) 对大树进行观察, 发现有不正常情况发生, 及时查找原因, 采取相应措施进行施救。

3. 4. 6施肥, 大树迁移后进行叶面喷肥, 7-10天 1 次, 连续 3 次。第一次喷施 $0.4 \%$ 尿素, 第二次喷0.4\%复合肥, 第三次喷 0. 4\%磷酸二氢钾。2019年 $4-5$ 月, 进行叶面喷肥 (喷施0. $4 \%$ 尿 素, 连续3次), 促进生长; 9-10月再进行叶面喷肥 (喷施0. 4\% 磷酸二氢(钾, 连续 3 次), 提高抗性。大树生根后, 进行施肥复 壮, 每年秋季 (10月底) 或3月初施基肥 (充分腐熟的有机肥及 生物菌肥), 每次在相对面开沟施肥, 连续进行两年。

3. 4. 7 管理性灌水, 每年3月上中旬浇透春水, 11 月中下 旬浇冻水。

\section{4 大树迁移注意问题}

4. 1 注意安全

大树迁移过程中, 一定注意人身安全, 周围建筑物等安全。

4. 2 防止散坨

大树散坨后, 严重影响成活, 在起挖、吊运、种植过程中, 一定规范操作, 防止方形土球散开。

4. 3 细致种植

种植时, 要随拆卸箱板随填土踩实, 做到根土密接, 种植 深度适宜。

4. 4 按时喷雾

树冠喷雾是保证大树成活的重要技术措施, 安排责任心 强的人进行树冠喷雾养护工作。

4. 5专人负责养护

设专人在两年内负责大树的养护管理及复壮, 专家定期 到现场指导, 进行科学合理的养护管理, 促进大树成活并尽 快恢复生长。

\section{[参考文献]}

[1]杨德兴, 大树移栽及栽后养护[J].林业使用技术,2007(9):43-45.

[2]孟兆祯,毛培琳, 黄庆喜, 园林工程 [M]. 北京: 中国林业 出版社,2002:19.

[3]刘志华, 周莉. 大树移植中存在的问题及对策[J]. 现代 农业科技,2008(12):78. 